\title{
Our View
}

\author{
K. Neil Harker, John T. O’Donovan, Robert E. Blackshaw, Hugh J. Beckie, C. Mallory-Smith, and Bruce D. Maxwell*
}

Perhaps the incidence and impact of glyphosate-resistant weed species are now great enough that real solutions to glyphosate resistance can be discussed without much backlash. It is clear to most weed scientists who are involved in herbicide research, and even those who are not, that the best way to reduce selection pressure for herbicide resistance is to minimize herbicide use. However, the "solutions" that have emerged in most recent meetings on herbicide resistance have usually involved more herbicide use-herbicide rotation, tank-mixtures, PRE- followed by POST-herbicides, "right-rates," etc. To an unbiased observer, it would appear that many weed emperors are wearing no clothes. Are we as a weed science discipline choosing to ignore true integrated solutions to the herbicide resistance problem?

Why are so many weed scientists and extension personnel recommending more herbicides to mitigate herbicide resistance problems? One speaker at a 2011 WSSA weed resistance meeting noted that because of his funding sources, it was difficult to talk about real solutions. At the same meeting, another expert suggested that the solution to herbicide resistance "all sits on herbicide diversity." At a 2010 meeting of Pan-American and European weed scientists, the nearconsensus solution for glyphosate resistance presented by speakers was to use glufosinate in the place of glyphosate. Industry strategy to manage glyphosate-resistant weeds is to develop crops with "stacked" herbicide-resistance traits (Green and Castle 2010; Wright et al. 2010). This technology might have short-term benefits in terms of delaying resistance evolution and spread, but over the long term, the benefits of these approaches could be minimal. Multiple resistance to herbicides with different sites of action has occurred in the past (Heap 2011) and will increasingly occur in the future. Negative environmental impacts from new herbicide-resistant crops are also possible (Egan et al. 2011; Mortensen et al. 2012). These solutions are nothing more than "integrated herbicide management" typical of the "other IPM" (integrated pest management) (Ehler 2006); they are NOT integrated weed management.

Although it is clear that modern agriculture benefits in many cases from the use of herbicides for a high level of weed control, soil conservation and sustainable yields, it is not clear that the weed science discipline should only be looking to herbicides for sustainable weed control solutions, particularly solutions for weed resistance to herbicides. Surely, weed management diversity involves more than herbicide diversity. "Respect the rotation" should mean more than the herbicide rotation.

Without a doubt, the introduction of glyphosate and other herbicide-resistant crops has been a tremendous boon to crop production in North America and other regions of the world. Indeed, glyphosate might have delayed the evolution of weed resistance to other herbicides and mitigated their resistance impact. However, one major downside has been the escalation of resistance to glyphosate in many weed species (Heap 2011).

\footnotetext{
DOI: 10.1614 /WS-D-11-00177.1

* First and second authors: Research Scientists, Agriculture and Agri-Food Canada (AAFC), Lacombe Research Centre, 6000 C \& E Trail, Lacombe, Alberta, Canada T4L 1W1; third author: Research Scientist, AAFC, Lethbridge, Alberta, Canada T1J 4B1; fourth author: Research Scientist, AAFC, Saskatoon, Saskatchewan, Canada S7N 0X2; fifth author: Professor, Oregon State University, Corvallis, OR 97331-3002; and sixth author: Professor, Montana State University, Bozeman, MT 59717. Corresponding author's E-mail: neil.harker@agr.gc.ca
}

The reason is obvious. Glyphosate is being used far more than it was in the past with a resultant increase in selection intensity.

There needs to be greater crop rotational diversity, which tends to decrease the dominance of individual weed species and often leads to the use of herbicides with different sites of action. For example, the glyphosate-resistant canola system was introduced to western Canada in 1995; yet to date, there is no evidence of weed resistance to glyphosate. There are likely several reasons for this, one being the availability and use of alternative systems, e.g., glufosinate- and imidazolinoneresistant canola. However, significant crop rotational diversity in western Canada also has decreased selection intensity. Because of disease issues, growers do not usually plant canola sequentially; they rotate canola with cereal or pulse crops. It is only a matter of time, however, before resistance is likely to appear in this system unless the number of in-crop glyphosate applications is reduced. In a canola study, there was little or no advantage to applying glyphosate more than once in-crop (O'Donovan et al. 2006), yet growers generally are not encouraged to limit application frequency in canola or other glyphosate-resistant crops; this behavior must change! Are we as a discipline so committed to maintaining profits for the agrochemical industry that we cannot offer up realistic longterm solutions to this pressing problem?

More research on herbicide alternatives is required. Research on allelochemicals and biofumigants, diverse crop rotations, higher crop seeding rates, intercropping, competitive cultivars and planting patterns, physical weed control, weed seed destruction, and reducing weed seed and vegetative propagule dormancy is crucial for a sustainable future. Combinations of a diversity of tactics in integrated crop management systems augment herbicide-based weed control (Harker et al. 2009) and lengthen the useful life of valuable herbicide tools.

Apparently, herbicides are a nonrenewable resource. No major herbicide sites of action have been introduced in the past $20 \mathrm{yr}$ (Duke 2011), few new herbicide sites of action are on the horizon, and weed resistance to glyphosate and other herbicides is a "tsunami" still out to sea but approaching land. The time has come to consider herbicide-frequency reduction targets in our major field crops-not just for environmental reasons but for economic reasons. Tinkering around the periphery of the glyphosate resistance problem is clearly too little, too late.

\section{Literature Cited}

Duke, S. O. 2011. Comparing conventional and biotechnology-based pest management. J. Agric. Food Chem. 59:5793-5798. 
Egan, J. F., B. D. Maxwell, D. A. Mortensen, M. R. Ryan, and R. G. Smith. 2011 2,4-dichlorophenoxyacetic acid (2,4-D)-resistant crops and the potential fo evolution of 2,4-D-resistant weeds. Proc. Natl. Acad. Sci. USA 108 E37; doi: 10.1073/pnas.1017414108 PNAS March 15, 2011 vol. 108, no. 11 E37.

Ehler, L. E. 2006. Integrated pest management (IPM): definition, historical development and implementation, and the other IPM. Pest Manag. Sci. 62:787-789.

Green, J. M. and L. A. Castle. 2010. Transitioning from single to multiple herbicide-resistant crops. Pages 67-91 in V. K. Nandula, ed. Glyphosate Resistance in Crops and Weeds. Hoboken, NJ: John Wiley \& Sons.

Harker, K. N., J. T. O’Donovan, R. B. Irvine, T. K. Turkington, and G. W. Clayton. 2009. Integrating cropping systems with cultural techniques augments wild oat (Avena fatua) management in barley (Hordeum vulgare). Weed Sci. 57:326-337.
Heap, I. M. 2011. The International Survey of Herbicide Resistant Weeds. http://www.weedscience.org. Accessed: October 2011.

Mortensen, D. A., J. F. Egan, R. G. Hartzler, B. D. Maxwell, M. R. Ryan, and R. G. Smith. 2012. Navigating a critical juncture for sustainable weed management. BioScience. 62:75-84.

O'Donovan, J. T., K. N. Harker, G. W. Clayton, and R. E. Blackshaw. 2006. Comparison of a glyphosate-resistant canola (Brassica napus L.) system with traditional herbicide regimes. Weed Technol. 20:494-501.

Wright, T. R., G. Shan, and T. A. Walsh, et al. 2010. Robust crop resistance to broadleaf and grass herbicides provided by aryloxyalkanoate dioxygenase transgenes. Proc. Natl. Acad. Sci. USA 107:20240-20245.

Received October 20, 2011, and approved November 30, 2011. 